\title{
The accuracy of determining newborn's maturity between New Ballard's score, Ballard's score, and first day of last menstrual period
}

\author{
Ferdy Limawal, Djauhariah A. Madjid, Dasril Daud
}

\begin{abstract}
Background Developing country such as Indonesia needs a tool to assess gestational age which is simple, practical, cheap, fast, and accurate. In 1991 the Ballard maturation score was refined and expanded to achieve greater accuracy and called New Ballard score.

Objective The purpose of this study was to determine the correlation between gestational age assessed by New Ballard score, Ballard score, and by the first day of last menstrual period (LMP). Methods A cross sectional study has been carried out in Dr. Wahidin Sudirohusodo, Ibnu Sina, Labuang Baji, and St. Fatimah Hospitals in Makassar, from July 1'st, 2006 until January 31 2007. This study included healthy newborns, aged 15 minutes to 24 hours born to mothers who knew with certainty the first day of their LMP. Diagnostic test was used to analyze the data.

Results There were 248 subjects included in this study. The results showed that there was a strong correlation between gestational age by LMP and New Ballard score $(r=0.97)$, LMP and Ballard score $(r=0.95)$, as well as between New Ballard score and Ballard score $(r=0.99)$. New Ballard score was more accurate and had a higher association coefficient $(k=0.85)$ than did Ballard score $(k=0.82)$ to LMP in identifying premature baby. The sensitivity of New Ballard score to identify premature baby was $87.7 \%$, specificity $96.3 \%$, positive predictive value $95.2 \%$ and negative predictive value $90.2 \%$.

Conclusions New Ballard score can be used to replace Ballard score if LMP can not be assessed. Further study needs to be done with bigger sample, involving other paramedics and unhealthy newborn babies. [Paediatr Indones 2008;48:59-63].
\end{abstract}

Keywords: New Ballard Score, Ballard Score, First day of last menstrual period.

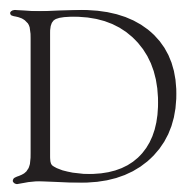
eveloping country like Indonesia needs a tool to assess of gestational age that is simple, practical, cheap and fast but accurate. In 1991 the Ballard maturation score was refined and expanded to achieve greater accuracy and to include extremely premature neonates, which can assess gestational age since 20 weeks called New Ballard Score. ${ }^{1}$ There were still a lot of controversies about the precise of New Ballard score in assessing gestational age..$^{2-4}$

The purpose of this was to determine the correlation between gestational age assessed by New Ballard score, Ballard score and by LMP and to evaluate the accuracy of New Ballard / Ballard score in detecting prematurity.

\section{Methods}

This cross sectional study was conducted in the Department of Child Health, Medical School,

From the Department of Child Health, Medical School, University of Hasanuddin, Dr. Wahidin Sudirohusodo Hospital, Makassar, Indonesia.

Reprint request to: Ferdy Limawal, MD, Department of Child Health, Medical School, University of Hasanuddin, Dr. Wahidin Sudirohusodo Hospital, Makassar, Indonesia. Tel. 62-411-584461. Fax. 62-411-590629. 
University of Hasanuddin, Wahidin Sudirohusodo, Ibnu Sina, Labuang Baji and St. Fatimah Hospitals, Makassar, Indonesia, from July $1^{\text {st }}, 2006$ until January 31 $1^{\text {st }}$, 2007. Written informed consent was obtained from parents. Ethical approval for this study was granted by The Committee for Medical Research Ethics of Medical School, University of Hasanuddin

Quality control was done before this study was started. New Ballard score and Ballard score examinations were done triplicate by investigators and the results were compared with neonatologist findings to see intra- and inter-examiner variation. The results of variation coefficient were $<0.1 \%$. A minimum sample size was 205. The inclusion criteria were healthy newborns, born to mothers who knew with certainty their LMP, the baby's age was 15 minutes to 24 hours. Subjects were excluded if they had congenital anomaly. Study subjects were recruited consecutively. Sequence of gestational age examination was taken randomly using table of random sampling numbers. Some subjects underwent the examination using New Ballard score first followed by Ballard score and the others did conversely. Two hours after the first examination, the second examination was done. After New Ballard score and Ballard score had been done then LMP was counted.

Pearson correlation, $\mathrm{X}^{2}$ marginal analyses was used. Association coefficient and accuracy of New Ballard score/Ballard score to diagnose premature baby were analyzed. Diagnostic test was used to analyze the data.

\section{Results}

There were 248 subjects included in this study, consisted of 115 premature babies, 121 mature babies and 12 post mature babies. There were 17 babies with gestational age $<26$ weeks, which only could be determined by New Ballard score and LMP. Subjects characteristics are shown in Table 1.

Sample distributions on this study were not evenly distributed. The gestational age was between 20 to 45.14 weeks, mostly were 38 to 41 weeks (Table 2).

Pearson correlation showed that there were strong correlations between LMP and New Ballard score (Figure 1), LMP and Ballard score (Figure 2) and between New Ballard score and Ballard score (Figure 3).
There was no difference between New Ballard score and LMP to identify premature baby. Sensitivity of New Ballard score to identify premature baby was $87.7 \%$, specificity $96.3 \%$, positive predictive value 95.2\% and negative predictive value 90.2\% (Table $3)$.

There was a difference between Ballard score and LMP to identify premature baby. Sensitivity of Ballard score to identify premature baby was $84.5 \%$, specificity $96.3 \%$, positive predictive value $94.2 \%$ and negative predictive value $89.6 \%$ (Table 4 ).

Table 1. Characteristics of study subjects

\begin{tabular}{lc}
\hline & $\mathrm{n}=248$ \\
\hline Sex & \\
Boys & $123(49.6 \%)$ \\
Girls & $125(50.4 \%)$ \\
Birth Weight (g) & 2296.3 \\
Mean & 2400 \\
Median & $530-4250$ \\
Range & 974.5 \\
Standard deviation & \\
Delivery & $208(83.9 \%)$ \\
Spontaneous & $6(2.4 \%)$ \\
Vacuum extraction & $34(13.7 \%)$ \\
Caesarian section & 27.3 \\
Mother's age (yr) & 27 \\
Mean & 5.2 \\
Median & $17-42$ \\
Standard deviation & \\
Range & $90(36.3 \%)$ \\
Parity & $143(57.7 \%)$ \\
Primipara & $15(6.0 \%)$ \\
Multipara & \\
Grande multipara & \\
\hline
\end{tabular}

Table 2. Distribution of subjects based on gestational age

\begin{tabular}{lccc}
\hline \multirow{2}{*}{$\begin{array}{c}\text { Gestational age } \\
\text { (Week) }\end{array}$} & \multicolumn{3}{c}{ Measuring Method } \\
\cline { 2 - 4 } & $\begin{array}{c}\text { LMP } \\
(\mathrm{n}=248)\end{array}$ & $\begin{array}{c}\text { New Ballard } \\
\text { Score } \\
(\mathrm{n}=248)\end{array}$ & $\begin{array}{c}\text { Ballard Score } \\
\left.\mathrm{n}=231+17^{*}\right)\end{array}$ \\
\hline $20-21$ & 2 & 0 & - \\
$22-23$ & 6 & 4 & - \\
$24-25$ & 9 & 10 & - \\
$26-27$ & 12 & 11 & $8\left(+17^{\star}\right)$ \\
$28-29$ & 15 & 12 & 12 \\
$30-31$ & 17 & 18 & 18 \\
$32-33$ & 18 & 23 & 23 \\
$34-35$ & 23 & 16 & 16 \\
$36-37$ & 35 & 31 & 31 \\
$38-39$ & 55 & 61 & 57 \\
$40-41$ & 42 & 36 & 41 \\
$42-43$ & 12 & 24 & 23 \\
$44-45$ & 2 & 2 & 2 \\
\hline
\end{tabular}

* There were 17 babies which gestational aged $<26$ weeks based on LMP, but the gestational age was 26 weeks. 
Ferdy Limawal et al: Gestational assesment by new Ballard score and Ballard score

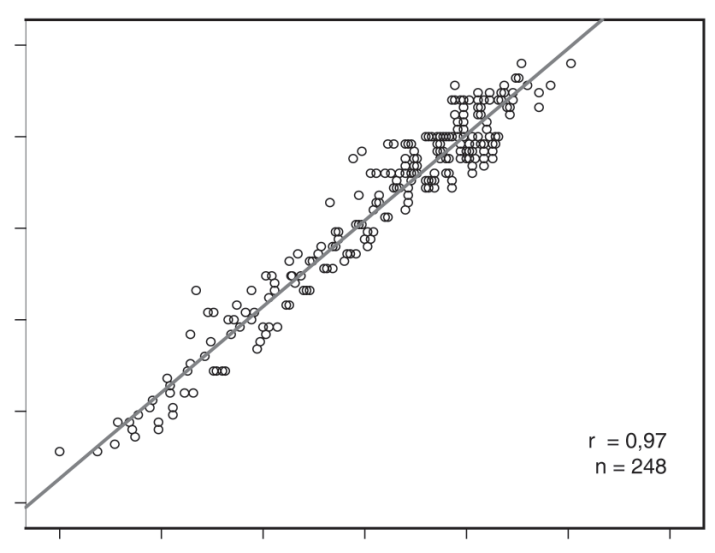

Figure 1. Correlation of gestational age between LMP and New Ballard Score

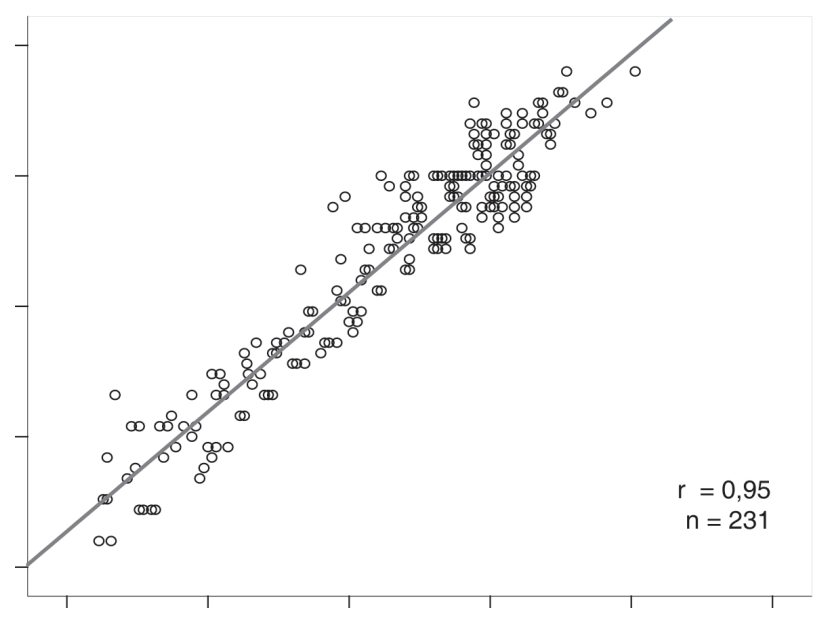

Figure 2. Correlation of gestational age between LMP and Ballard Score

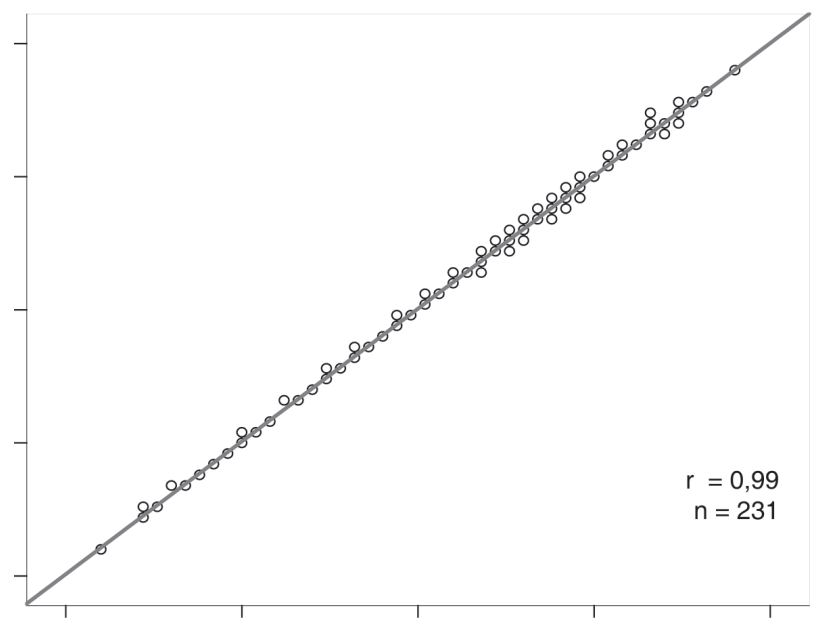

Figure 3. Correlation of gestational age between New Ballard Score and Ballard Score
Table 4. Diagnostic values of Ballard score to identify premature baby

\begin{tabular}{|c|c|c|c|}
\hline \multirow[t]{2}{*}{ Ballard Score } & \multicolumn{2}{|c|}{ LMP } & \multirow[t]{2}{*}{ Total } \\
\hline & Premature & $\begin{array}{c}\text { Mature \& } \\
\text { Post mature }\end{array}$ & \\
\hline Premature & 82 & 5 & 87 \\
\hline Mature \& Post-mature & 15 & 129 & 144 \\
\hline Total & 97 & 134 & 231 \\
\hline$X^{2}$ marginal $=4.05$ & & $P=0.04$ & \\
\hline
\end{tabular}

Table 3. Diagnostic values of New Ballard score to identify premature baby

\begin{tabular}{lccc}
\hline \multirow{2}{*}{ New Ballard Score } & \multicolumn{2}{c}{ LMP } & Total \\
\cline { 2 - 3 } & Premature & $\begin{array}{c}\text { Mature \& } \\
\text { Post mature }\end{array}$ \\
\hline Premature & 100 & 5 & 105 \\
Mature \& Post-mature & 14 & 129 & 143 \\
\hline Total & 114 & 134 & 248 \\
\hline$X^{2}$ marginal $=3.37$ & $\mathrm{P}=0.06$ & &
\end{tabular}

New Ballard score was more accurate and had a higher association coefficient $(k=0.85)$ than did Ballard score $(k=0.82)$ to LMP in identifying premature baby.

\section{Discussion}

The most accurate method to assess gestational age is that using LMP., ${ }^{5}$ In this study LMP was used as the gold standard. This study showed that there was a strong correlation between LMP and New Ballard score $r=0.97$. This was consistent with the results of Ballard et $a l^{1}$ in $1991(r=0.97)$. There was a strong correlation between LMP and Ballard score $r=0.95$. This result was better than that of Ballard et $\mathrm{al}^{7}(r=$ $0.85)$ and $\operatorname{Yusran}^{8}(r=0.72)$.

The principal difference between New Ballard Score and Ballard Score was that in New Ballard score there was minus score therefore it can assess gestational age since 20 weeks, ${ }^{1}$ whereas Ballard Score can only assess gestational age since 26 weeks. ${ }^{7}$ To avoid wrong correlation analysis between New Ballard score and Ballard score we included the babies with gestational age $=26$ weeks according to LMP.

The result of correlation analysis between New Ballard score and Ballard score was very good $r=0.99$. This excellent correlation is easy to understand 
because in principal, all the criteria between New Ballard score and Ballard score was identical, only few scores were refined and expanded to achieve greater accuracy.

Sensitivities of New Ballard score to identify premature babies in this study was higher than those reported by several other studies. Alexander et a $l^{9}$ reported sensitivity of $72.2 \%$, specificity of $97.1 \%$, positive predictive value of $83.2 \%$ and negative predictive value of $94.6 \%$. According to Moraes et allo the sensitivity of New Ballard score to identify premature babies was $<70 \%$ and the specificity was $90 \%$.

The result of $\mathrm{X}^{2}$ marginal analysis showed that there was a difference between Ballard score and LMP to identify premature babies. There were several reasons that can explain this:

1. The subject were not evenly distributed.

2. There were 17 premature babies with $<26$ weeks of gestational age which were all graded as 26 weeks by Ballard score, which not included in the statistical analysis. If these 17 babies were included in the statistical analysis, the result would not be different.

There were a lot of babies with 36 weeks of gestational age (premature baby) which were graded as 37 weeks (mature baby) by Ballard score or vise versa. This little difference can make Ballard score failed to identify premature baby. This phenomenon was admitted by Ballard et al that little difference between 36 to 37 weeks of gestational age can influence the accuracy significantly. ${ }^{1}$ However in clinical application, this little difference of gestational age (1 week in range) had no big effect on treatment and prognosis of newborn babies. ${ }^{11}$

Overall, even though New Ballard score and Ballard score had excellent correlation, but New Ballard score was better than Ballard score, because:

1. Correlation between New Ballard score with LMP was stronger than that with Ballard score.

2. New Ballard score was more accurate in detecting premature baby. The sensitivity of New Ballard score to identify premature baby was higher than those of Ballard score.

3. New Ballard score had a higher association coefficient than did Ballard score to LMP in identifying premature baby.
There were several limitations in this study such as bias in LMP still might be happen. Further more, subject with gestational age $<26$ weeks were very few. This study was done only by one investigator and include only healthy babies. Further studies to see whether the accuracy was still good if other paramedics and unhealthy newborn babies were involved.

In conclusion, New Ballard score could be performed to replace Ballard score if LMP can not be assessed. Further study with bigger samples size involving others paramedics and unhealthy newborn baby is needed to be done.

\section{References}

1. Ballard JL, Khoury JC, Wedig K, Wang L, Eilers-Walsman BL, Lipp R. New Ballard Score expanded to include extremely premature infants. J Pediatr 1991;119:417-23.

2. Donovan EF, Tyson JE, Ehrenkranz RA, Verter J, Wright LL, Korones SB. Inaccuracy of Ballard scores before 28 weeks' gestation. National Institute of Child Health and Human Development Neonatal Research Network. J Pediatr 1999;135:137-9.

3. Gabriel MMA. Assessment of the new Ballard score to estimate gestational age. Ann Pediatr 2006;64:140-5.

4. Smith LN, Dayal VH, Monga M. Prior knowledge of obstetric gestational age and possible bias of Ballard score. Obstet Gynecol 1999;93:712-4.

5. Gomella TL. Assessment of weight and gestational age. In: Gomella TL, Cunningham MD, Eyal FG, Zenk KE, editors. Neonatology: management, procedures, on-call problems, diseases, and drugs. $4^{\text {th }}$ ed. New York: McGraw-Hil Co; 1999. p. 21-8.

6. Thilo EH, Rosenberg AA. The newborn infant. In: Hay WW, Hayward AR, Levin MJ, Sondheimer JM, editors. Current pediatric diagnosis and treatment. $16^{\text {th }}$ ed. New York: McGraw-Hill Companies; 2003. p. 1-7.

7. Ballard JL, Novak KK, driver M. A simplified sore for assessment of fetal maturation of newly born infants. J Pediatr 1979;95:769-74.

8. Yusran Y. Correlation of gestational age between LMP, Dubowitz Score and Ballard Score [Thesis]. Makassar: Department of Child Health, Hasanuddin University; 1995.

9. Alexander GR, de Caunes F, Hulsey TC, Tompkins ME, Allen M. Validity of postnatal assessments of gestational age: a comparison of the method of Ballard et al. and early ultrasonography. Am J Obstet Gynecol 1992;166:891-5. 
Ferdy Limawal et al: Gestational assesment by new Ballard score and Ballard score

10. Moraes CL, Reichenheim ME. Validity of neonatal clinical assessment for estimation of gestational age: comparison of new Ballard score with date of last menstrual period and ultrasonography. Cad Saude Publica 2000;16:83-94.
11. Stoll BJ, Kliegman RM. Overview of Mortality and morbidity. In: Behrman RE, Kliegman RM, Jenson HB, editors. Nelson textbook of pediatrics. $17^{\text {th }}$ ed. Philadelphia: WB Saunders Co; 2004. p. 519-23.

\section{Editor's comment:}

The Editor is of the opinion that calculating Pearson correlation of the results of 2 measurements on one variable is not a proper way to analyze the data. This will eventually result in a very high correlation but it does not mean that the 2 measurements are identical or interchangeable. 